* Doutoranda no Programa de Pós-Graduação em Sociologia e Direito da Universidade Federal Fluminense (PPGSD/UFF). Mestre em Ciências Jurídicas e Sociais pelo PPGSD/UFF. Advogada. E-mail: danjulsil@ yahoo.com

** Doutor em Sociologia pelo Instituto Universitário de Pesquisas do Rio de Janeiro - SBI/IUPERJ, Vice-Diretor do Instituto de Ciências Humanas e Filosofia (ICHF) da Universidade Federal Fluminense. Graduado em Direito pela Universidade Cândido Mendes - UCAM. Email: napomiranda@ uol.com.br

\section{Micro e pequenas empresas contratadas do terceiro setor contratante de obras e serviços públicos}

\author{
MicRo AND SMALL ENTERPRISES IN THEIR \\ CONTRACTS WITH THE THIRD SECTOR \\ RESPONSIBLE FOR PUBLIC SERVICES
}

* Daniela Juliano Silva

** Napoleão Miranda

Resumo: Em um cenário de sucessivas mutações, nos deparamos hoje com um "novo" desenho de Estado (Primeiro Setor), subsidiário e fomentador, abarcando novos modelos de contratação, que envolvem instituições privadas sem fins lucrativos (Terceiro Setor) à frente de serviços sociais de relevância (saúde, educação, tecnologia, dentre outros). Para cumprir com as obrigações firmadas com o ente público (obrigações-fim), este Terceiro Setor realiza contratações (para realizar suas obrigações-meio) com o Segundo Setor (Mercado), donde se inserem Microempresas e Empresas de Pequeno Porte. O presente estudo pretende um olhar reflexivo sobre estas contratações, geralmente fruto de processos licitatórios simplificados, a fim de verificar suas especificidades e se as mesmas se dão com observância das prerrogativas e do tratamento diferenciado especialmente dispensado àquelas sociedades empresárias (art. 170, X, CF/1988). Nesta empreitada, optou-se, afora uma revisão bibliográfica, por uma abordagem investigativa, sob o ponto de vista de três organizações sociais distintas que possuem contratos de gestão na área da saúde com entes públicos e, portanto, firmam contratos com ME e EPP para a realização de suas obrigações junto ao poder público.

Palavras-chave: Microempresas e Empresas de Pequeno Porte; Contratos com o Terceiro Setor.

Abstract: A new perspective in the design of the State figure (as known as the First Sector) reinforces the new models of contractions, involving private, nonprofit institutions (as known as the Third Sector) ahead relevant public services (in health, education, technology). In order to fulfill their obligations into the promotion of those public services, the Third Sector contracts with micro and small enterprises (as known as the Second Sector). This study intends a glance into the dynamic of 
those contractions, in order to realize if their rules respect the privileges that micro and small enterprises has in Brazilian law regulations and if those privileges are really making any difference in the reality of the relation between micro and small enterprises and the third sector. Apprehending an exploratory effort we choose three different social organizations, in order to realize the dynamic of those contractions.

Keywords: Micro and small enterprises. Third Sector; Contracts in public services. 


\section{INTRODUÇÃO}

Primeiramente, é necessário contextualizar o cenário no qual pretendemos nos debruçar. É preciso, portanto, antes de qualquer outra digressão, apontar para as dificuldades terminológicas e conceituais que, invariavelmente, circundam a temática ora abordada. Existe uma enormidade de variáveis ao falarmos do Terceiro Setor e, neste momento, julgamos prudente pontuarmos acerca das mais recorrentes. Nesta ordem, vale reforçar o recursivo pensamento de que o Terceiro Setor deveria, em verdade, receber a denominação de Primeiro Setor (RIFKIN, 2005, p. 19), vez que a sociedade teria surgido antes do Estado e do Mercado. Alguns autores (MONTAÑO, 2005), condenam a divisão entre Primeiro, Segundo e Terceiro setor, "construído a partir de um recorte social em esferas" (MONTAÑO, 2005, p. 53), de matizes claramente neopositivistas, que as distanciaria da realidade social, impondo um conceito reducionista, “como se o 'político' pertencesse à esfera estatal, o 'econômico' ao âmbito do mercado e o 'social' remetesse apenas à sociedade civil” (MONTAÑO, 2005, p. 53).

Existe ainda, a crítica terminológica no sentido da confusão que poderia advir do termo Terceiro Setor, em contraposição ao termo Setor Terciário (COELHO, 2003, p. 43). Finalmente, instaura-se recorrente conflito no sentido de que, por se portar em franca oposição ao Estado e ao Mercado, o Terceiro Setor não pertenceria nem à esfera do público, nem à esfera do privado, recebendo as mais diferenciadas nomenclaturas: "público porém privado" (MONTAÑO, 2005, p. 18); "privado porém público" (FERNANDES, 1994, p. 13); "a atividade pública desenvolvida pelo setor privado" (IOSCHPE, 2005, p. 14); o "público não-estatal” (BRESSER PEREIRA; GRAU, 1999, p. 21); "setor específico" (PIMENTA; SARAIVA; CORRÊA, 2008, p. 11).

Outra questão que acreditamos merecer, de pronto, alguma reflexão, diz respeito à menção no título deste estudo ao termo "serviços públicos", que em si suportaria estudo próprio. Como veremos mais adiante, o Terceiro Setor começa a se perpetuar no cenário brasileiro com o Plano Diretor de Reforma do Aparelho Estatal, (BRASIL, 1995), e especialmente com a classificação ali eternizada que consagrou aos entes do Terceiro Setor o "Setor de serviços não-exclusivos do Estado”. Nesta medida, os entes do Terceiro Setor não estariam a frente de serviços públicos "exclusivos", o que não os submeteria aos ditames do regime jurídico de direito público, com seus processos e procedimentos peculiares. Sendo assim, o uso do termo "serviços 
públicos" no título deste trabalho traz consigo impropriedades que não pretendemos enfrentar, nem muito menos esgotar. O termo deve ser compreendido da forma mais popularizada possível, especialmente pela onipresença do Terceiro Setor na realização de direitos sociais de peso.

Desta feita, deixando um pouco de lado todas as ponderações acima explicitadas, na tentativa de delimitarmos o objeto no qual nos debruçaremos, superando as polêmicas e divergências conceituais e terminológicas, entenderemos por Terceiro Setor, de forma bem simplificada (e direcionada), aquelas pessoas jurídicas de direito privado, sem fins lucrativos, que, via contratos com o poder público, realizam serviços públicos de relevância. Nesta relação, por fim, interessa-nos o cenário onde se formalizam os "contratosmeio" (limpeza, vigilância, refeições, dentre outros), que viabilizarão o fim público. Nesta ordem, lançaremos um olhar sobre os processos de compras firmados entre os entes do Terceiro Setor e os entes do Segundo Setor, em especial, os perpetrados entre microempresas e empresas de pequeno porte (ME's e EPP's).

Neste cenário, empreende-se, primeiramente, uma revisão bibliográfica dos principais temas que importam à matéria, levando em conta, neste sentido, o contexto das micro e pequenas empresas no cenário brasileiro, seus privilégios normativos e principais expectativas. No desenvolvimento bibliográfico, empreende-se também um esforço de contextualização da figura do Terceiro Setor sob a ótica de seus principais marcos teóricos, no que citamos, Gustavo Justino de Oliveira (2008) e José Anacleto Abduch Santos (2007).

Ainda em termos metodológicos, por meio da competente pesquisa exploratória, pretende-se verificar a relação entre ME's e EPP's com o Terceiro Setor, com foco especial nos processos de compras de obras e serviços de responsabilidade deste (no que citamos, os serviços de fornecimento de refeições, limpeza, vigilância). Nesta dinâmica, interessa-nos verificar quais são os métodos e como se dão as contratações, geralmente fruto de processos licitatórios "simplificados", promovidos pelos entes do Terceiro Setor e, se os mesmos acontecem em respeito ao tratamento favorecido dispensado às sociedades empresárias ora foco de nosso estudo. Desta feita, realiza-se um estudo comparativo entre três Organizações Sociais (OS's) representantes deste Terceiro Setor - (Missão Sal da Terra (MG), IABAS (RJ) e VIVA RIO SAÚDE - VIVA Comunidade (RJ) - com o intuito de verificar o comportamento destes entes na sua relação prática com micro e pequenas empresas. 
Nesta medida, no desenvolvimento do tema, parte-se, no primeiro tópico, para uma análise preliminar acerca das prerrogativas e privilégios das ME's e EPP's e o cenário do empreendedorismo no Brasil. Na sequência, passase, obrigatoriamente, por todo o processo que culminou na mudança do paradigma estatal, com o maior comprometimento da sociedade civil e do direcionamento do que se entenderia por Terceiro Setor.

Finalmente, no último tópico deste estudo, tendo-se optado por uma abordagem investigativa, concretiza-se a pesquisa empírica, com a análise dos processos de compras das três Organizações Sociais municipais acima mencionadas (uma no Estado de Minas Gerais e as outras duas no Estado do Rio de Janeiro), a fim de verificar se as mesmas se dão com respeito às prerrogativas afetas às ME's e EPP's, e se essas têm conseguido se destacar nestas dinâmicas de contratação.

\section{MICROEMPRESAS E EMPRESAS DE PEQUENO PORTE - PERSPECTIVAS E PRIVILÉGIOS}

Desde 2000, O Brasil participa da GEM - Global Entrepreneurship Monitor, pesquisa de âmbito mundial, que pretende o levantamento de dados dos países envolvidos (em 2012, foram 69 países), a fim de verificar as condições para o desenvolvimento de novos negócios. Por aqui, a pesquisa é conduzida pelo Instituto Brasileiro da Qualidade e Produtividade - IBPQ - e conta com a parceria do Serviço Brasileiro de Apoio às micro e pequenas empresas - SEBRAE. Em 2012 o GEM Brasil ${ }^{1}$ apresentou curiosidades (e novidades) ao demonstrar, por exemplo, que o sonho de ter um negócio próprio, superou o sonho dos brasileiros de fazer carreira em uma empresa. A realidade limitadora dos negócios no Brasil, com impostos e sistemas burocráticos sem igual, tolhem a plena capacidade empreendedora do país, servindo o universo das micro e pequenas empresas como experiência para construção de novas possibilidades.

Como fizemos questão de direcionar em nossas considerações introdutórias, nos interessa pontuar nestas linhas o tratamento diferenciado recebido pelas Microempresas e Empresas de Pequeno Porte em nosso ordenamento, reconhecendo o esforço do legislador brasileiro de favorecer o empreendedorismo no país. Tal direcionamento inicial se faz necessário, na

1 GEM Brasil 2012 disponível em http://bis.sebrae.com.br/GestorRepositorio/ARQUIVOS_CHRONUS/ bds/bds.nsf/9696c98c23d137fd0d8af1300d9742b0/\$File/4226.pdf. 
medida em que nos interessa mais de perto conduzir o leitor a uma realidade contraposta, que parece deixar em segundo plano quaisquer privilégios daqueles entes quando da relação com o dito Terceiro Setor.

A Constituição Federal de 1988, especialmente em seus artigos 170, IX e 179, delimita claramente a pretensão de se dar às microempresas e empresas de pequeno porte um tratamento especial a fim de que se concretize efetivamente toda a sua força empreendedora. Os artigos constitucionais reafirmam a potência de micro e pequenas empresas no universo do empreendedorismo brasileiro, como sociedades que representam a maior fatia deste universo.

Nesta ordem, enquanto a Constituição Federal faz as vezes de mandatária deste tratamento favorecido, a Lei Complementar n. 123, de 14 de dezembro de 2006, que veio instituir o Estatuto Nacional da Microempresa e da Empresa de Pequeno Porte, é quem dita as normas gerais de seu tratamento diferenciado. Tais prerrogativas se dão, especialmente, nos processos de contratação pública, a exemplo do direito de comprovar condição de regularidade fiscal apenas por ocasião da contratação e o direito de preferência no caso de empate nos processos licitatórios (arts. 42 a 45). Bastaria, a princípio, para gozar destas prerrogativas, seu enquadramento como Microempresa (receita bruta igual ou inferior a $\mathrm{R} \$ 360.000,00$ anocalendário) ou como Empresa de Pequeno Porte (receita bruta superior a R \$ 360.000,00 e igual ou inferior a 3.600.000,00 ano-calendário).

É certo que não é o objetivo primeiro deste estudo tecer maiores considerações acerca das críticas existentes ao tratamento diferenciado dispensado a micro e pequenas empresas, especialmente no que diz respeito aos privilégios das mesmas no âmbito dos certames licitatórios estatuído pela LC 123/2006, mas não faltam autores (JUSTEN FILHO, 2007, p. 87) a conclamar as polêmicas por detrás de citado fomento constitucional.

No mais, poderíamos citar outras prerrogativas, principalmente de ordem tributária (art. 146, III, $d, \mathrm{CF} / 88$ ), mas o regime de tributação simplificado - SIMPLES também não guarda correlação com o objetivo que ora nos debruçamos, no sentido de descortinar as relações das micro e pequenas empresas no universo de contratações com o dito Terceiro Setor.

Desta feita, empreenderemos na sequência, algumas considerações mais aprofundadas acerca do Terceiro Setor (deixando de lado as polêmicas conceituais, terminológicas e ideológicas), a fim de melhor contextualizarmos o campo de reflexões inicialmente proposto. 


\section{O TERCEIRO SETOR}

Superadas as reflexões terminológicas e conceituais (tendo deixado de lado as questões ideológicas) que o denominado Terceiro Setor desperta, as quais fizemos questão de pontuar logo nas primeiras linhas deste estudo, pretendemos neste momento, uma incursão bastante generalizada acerca do que se venha a entender por Terceiro Setor (seu surgimento e desenvolvimento), a fim de delinearmos o cenário geral pelo qual caminhamos.

Nesta ordem, é importante reconhecer todas as mutações sofridas pelo Estado, que não mais realiza o exercício de suas competências públicas somente por intermédio dos órgãos da Administração Direta e das entidades da Administração Indireta (autarquias, empresas públicas, sociedades de economia mista e fundações públicas). Em um profícuo cenário de transformações e de consequente reforma administrativa, a sociedade civil se fortalece e ganha corpo através do denominado Terceiro Setor.

Neste processo de transformação do Estado contemporâneo que ora nos atrai, alguns elementos se destacaram: “(i) a cooperação mais ou menos sistemática e a conjugação ordenada dos papéis de actores públicos e privados no desenvolvimento das tradicionais finalidades do Estado Social e de Serviço Público; (ii) Sob o mote de uma 'modernização administrativa', um complexo processo de 'empresarialização' que, por vezes, passa pela 'privatização das formas organizativas da Administração Pública'; (iii) A promoção de mecanismos de envolvimento e de participação de particulares 'interessados' na gestão de um largo leque de incumbências públicas" (GONÇALVES, 2005, p. 27).

Diante deste cenário, passa a ganhar evidência uma sistemática estatal mais colaborativa, de um Estado fomentador, negocial, que vai em busca de parcerias para realizar de forma efetiva suas competências públicas e é nesta dinâmica que se estrutura e desabrocha o Terceiro Setor. Do inglês third sector, o Terceiro Setor se difundiu a partir da década de setenta, se referindo às organizações formadas pela sociedade civil, cujo objetivo maior é a satisfação do interesse social e não o mero lucro.

Em contraposição aos chamados Primeiro Setor (representado pela figura do Estado) e o Segundo Setor (Mercado), o Terceiro Setor é tradicionalmente entendido como área dentro da qual se encontram todas as entidades que não fazem parte do Estado nem do mercado. Sob a metodologia estabelecida pelo Handbook on nonprofit institutions in the system of 
national accounts, editado pela Organização das Nações Unidas, fariam parte do Terceiro Setor as entidades que detenham, cumulativamente: (i) natureza privada; (ii) ausência de finalidade lucrativa; (iii) institucionalizadas; (iv) auto-administradas; (v) voluntárias (SALAMON; ANHEIER, 1994, p. 79).

Apesar desta referência, ela não se presta à adoção de um conceito satisfatório à dogmática jurídica, mormente pela amplitude e pelos contornos assumidos pela matéria no cenário institucional pátrio. De toda forma, na tentativa de conceituar o Terceiro Setor uma concepção prevalece: a idéia de delegação social. É o que alerta Diogo Figueiredo Moreira Neto (2000, p. 124), ao inserir os entes do Terceiro Setor no que denomina entes intermédios, para os quais haveria a transferência de serviços de interesse público "[...] em favor de entes criados por ela própria sociedade, dedicados à colaboração no atendimento de interesses legalmente considerados como públicos".

Diante dos mais variados conceitos apresentados pela doutrina do que se entenda por Terceiro Setor, citamos o conceito de Gustavo Justino de Oliveira (2008, p. 46), por sua variedade de elementos, senão vejamos:

[...] o conjunto de atividades voluntárias, desenvolvidas por organizações privadas não-governamentais e sem ânimo de lucro (associações ou fundações), realizadas em prol da sociedade, independentemente dos demais setores (Estado e mercado), embora com eles possa firmar parcerias e deles possa receber investimentos (públicos e privados).

Na realidade brasileira, tal modelo surge, a princípio, pela prestação de serviços de interesse público pela Igreja Católica, por meio de confrarias e irmandades que, posteriormente, ganharam companhia de entidades criadas por outras igrejas e de associações de imigrantes. No século XX, frente aos processos de urbanização e industrialização, este quadro se alteraria sensivelmente. Surgem numerosas associações profissionais, associações de classe e sindicatos, como instrumentos de amparo ante a ausência de normas regulatórias das relações de trabalho.

Com a Constituição de 1934, o Estado brasileiro assume o modelo de Estado social, ocorrendo uma aproximação entre Estado e sociedade, caracterizada por um movimento de "socialização do Estado e estadualização da sociedade" (NOVAIS, 1987, p. 197), ou melhor, "[...] absorção da Sociedade pelo Estado, isto é, a politização de toda a sociedade" 
(BONAVIDES, 2003, p. 231). Como expressão máxima do modelo intervencionista de Estado, foram criadas nessa época, empresas públicas para atuação na área econômica, bem como foi ampliado o aparato estatal destinado à prestação de serviços sociais. Nesta perspectiva, surgem a Legião Brasileira de Assistência - LBA e os serviços sociais autônomos (entidades do chamado sistema " $S$ " - SENAI, SESI, SESC, SENAC, SEBRAE, SENAR), pessoas jurídicas de direito privado, mantidas por contribuições sociais e dotação orçamentária, com o objetivo de prestar educação profissional e assistência aos cidadãos vinculados ao setor produtivo.

Com a promulgação da Constituição de 1988 reconhece-se que, pela primeira vez, uma Constituição brasileira tratou de maneira expressa acerca da sociedade civil, atribuindo à mesma, em inúmeros dispositivos (art. 199, $\S 1^{\circ}$; art. 204, I; art. 205; art. 213, I e II; art. 216, $\S 1^{\circ}$; art. 227, $\S 1^{\circ}$ ), o dever de contribuição para a consecução dos objetivos do Estado brasileiro.

Neste panorama surge o Plano Diretor de Reforma do Estado que, adotando um modelo conceitual baseado na distinção de quatro setores específicos de ação estatal, conforme a natureza de suas atividades, associaos às modalidades de propriedade (pública, pública não-estatal e privada) e formas de gestão. Nestes setores, destacam-se um Núcleo estratégico, um Setor de atividades exclusivas do Estado, Setor de serviços não-exclusivos do Estado e um Setor de produção de bens e serviços para o mercado. O Terceiro Setor faria parte, em franca redundância, daquele terceiro Setor (Setor de serviços não-exclusivos do Estado). Como já fizemos questão de pontuar, a definição como "serviços não-exclusivos do Estado" norteia toda uma discussão sobre os limites da atuação do Terceiro Setor e o que lhe garantiria imprimir as características de uma gestão privada. Esta afirmação tem todo um peso na temática ora posta em reflexão, uma vez que, ao se entender que o Terceiro Setor presta "serviços públicos", estaria sujeito aos ditames do regime público.

No mais, citado Plano Diretor de Reforma do Estado previu a criação de entidades denominadas Organizações Sociais - OS's, exteriorizando a tentativa de redefinir o plano de relações entre o Estado e as entidades prestadoras de serviços de interesse público. Outras entidades destacaramse neste cenário, no que citamos, especialmente, a Organização da Sociedade Civil de Interesse Público - OSCIP. Tais entes, por intermédio das suas respectivas leis, se encontram à frente de ações na área da cultura, saúde, educação e tecnologia, meio ambiente, dentre outras. 
Como já antecipado, nos interessa mais de perto, a fim de reduzir o objeto de estudo uma reflexão acerca da realidade das Organizações Sociais (OS's), uma vez que nossa pesquisa exploratória foi empreendida segundo o dia a dia de Organizações Sociais e suas relações contratuais especialmente com ME's e EPP's.

A princípio, as Organizações Sociais surgiram para absorver as atividades desenvolvidas por entidades ou órgãos públicos, fator de sucessivas (e justificadas) críticas ao modelo. De toda forma, com o desenvolvimento da matéria e com o advento da Lei Federal 9.637/1998 muito se modificou e estas instituições privadas sem fins lucrativos se tornaram legitimadas a firmar parcerias com o Poder Público, via contratos de gestão. Uma vez que não é o foco principal deste estudo uma incursão aprofundada na lei das OS's, entendemos que valeria apenas ressaltar que, tais entes nada mais são, do que pessoas jurídicas de direito privado, sem fins lucrativos, que em razão do preenchimento de certos requisitos, receberam uma "qualificação" do Poder Público, que as legitima a realizar competências na esfera dos direitos sociais.

O nível de compromisso firmado nos respectivos contratos de gestão, com a necessidade de cumprimento de resultados e metas específicas, a realização de serviços sociais de relevância e o recebimento de recursos públicos promove a coexistência de regimes jurídicos diversos, ora público, ora privado. A princípio, as relações firmadas entre os entes públicos e estas organizações sociais se dão sob o manto de prerrogativas e cláusulas exorbitantes, típicas do regime público. Tais instituições não são independentes e autônomas como se pretende o discurso. Sujeitam-se, constantemente, ao controle de entes públicos (Ministério Público, Tribunais de Conta, Legislativo e do próprio ente contratante) e à apuração de seus atos de responsabilidade.

Em paralelo à relação que se estabelece entre o poder público e o ente do Terceiro Setor, surgem as relações que denominamos de "obrigaçõesmeio", firmadas com entes privados, pertencentes ao Segundo Setor (Mercado), cujos pormenores desenvolveremos na sequência.

\section{MICROEMPRESAS E EMPRESAS DE PEQUENO PORTE NOS PROCESSOS DE COMPRA DO TERCEIRO SETOR - TEORIA E PRÁTICA}

As reflexões até aqui esposadas se mostraram necessárias a fim de finalmente adentrarmos na dinâmica de contratações do Terceiro Setor e se 
as especificidades deste modelo trazem alguma consequência ou mesmo algum tipo de comprometimento ao tratamento diferenciado dado a Microempresas e Empresas de Pequeno Porte.

Como já antecipamos, um regime híbrido, típico das relações firmadas pelo Terceiro Setor, marcado por relações que orbitam entre o público e o privado, é frequentemente objeto de questionamentos e desconfiança, merecendo constante reflexão. Como repetidamente antecipado, a relação que nos interessa é a das "obrigações-meio" que se firmam com ME's e EPP's em um ambiente, em regra, estritamente privado. Os entes do Terceiro Setor, não podemos esquecer, são igualmente pessoas jurídicas de direito privado. Nestas bases, a princípio, não se justificaria qualquer diferença entre as partes, vez que ME's, EPP's e o Terceiro Setor estariam em pé de igualdade e em franco uso de sua autonomia privada.

Acontece que a questão não se desenvolve de maneira tão simples. $\mathrm{O}$ objeto dos contratos firmados entre os entes do Terceiro Setor e o poder público são de ordem pública e sua relevância é indiscutível. Além do mais, não se pode esquecer que na origem destas contratações está a transferência de recursos públicos, o uso de bens públicos e, eventualmente, a cessão de servidores públicos, não havendo como admitir a existência de uma gestão essencialmente privada ainda que a relação se instaure somente entre pessoas jurídicas de direito privado.

Exatamente por conta destas peculiaridades, imperativa a observância pelos entes do Terceiro Setor dos princípios que movem a Administração Pública, no que citamos: a moralidade, a transparência, a impessoalidade, a publicidade e a economicidade.

Em pronto respeito ao princípio da transparência e da máxima da publicidade, os entes do Terceiro Setor devem exteriorizar ao máximo todos os seus atos, no que se insere toda a sua sistemática de contratação. A fim de concretizar citadas máximas, tais entes devem respeito ao princípio licitatório, o que, se entenda bem, não significa estarem atrelados aos ditames da Lei Geral de Licitações (Lei 8.666/93). O princípio licitatório se firmaria, portanto, pela elaboração e registro de um Regulamento Próprio, instrumento apto a descrever as etapas e regras das contratações. José Anacleto Abduch Santos (2007, p. 302), em excepcional trabalho realizado na obra Terceiro Setor Empresas e Estado - Novas fronteiras entre o Público e o Privado, resume, nas linhas a seguir trasladadas, a exata medida destas afirmações: 
As normas para a seleção prévia aos contratos a serem firmados pelo Terceiro Setor com o uso de recursos públicos devem ser estabelecidas em regulamentos próprios. Estes regulamentos podem prever mecanismos simplificados e céleres de seleção, contanto que tenham conteúdo compatível com os princípios aplicáveis a estas entidades responsáveis pelo uso do dinheiro público. Não se exige, portanto, que os regulamentos próprios das entidades repitam as normas da lei das licitações. Dentro da moldura constitucional há espaço para inovações, sem que haja vinculação expressa a procedimentos formais da Lei n. 8666/93. Este espaço criativo foi assegurado pelo legislador, eis que de outro modo teria feito constar taxativamente a aplicação da referida lei das licitações a estas entidades. A elaboração dos regulamentos próprios constitui conduta revestida de singular natureza e especificidade. A sua concepção será fruto de um processo de tensão dialética que assegure a celeridade e dinamicidade próprias do regime de direito privado, sem descurar dos valores e princípios fundamentais ao regime de direito público, em especial, neste caso, no tocante à gestão de recursos públicos, à busca da proposta mais vantajosa, e ao princípio da isonomia. (SANTOS, 2007, p. 302, grifo nosso).

Empreendendo um trabalho investigativo, optamos por um levantamento do processo de compras de três organizações sociais que possuem contratos de gestão com seus respectivos municípios para gestão de ações na área de saúde, em sendo: VIVA RIO SAÚDE - VIVA Comunidade (RJ), IABAS Instituto de Atenção Básica e Avançada à Saúde (RJ) e a Missão Sal da Terra (MG). Primeiramente (em maio/2013), foi feita uma investigação contrapondo as realidades do IABAS (RJ) com a Missão Sal da Terra (MG). Diante dos resultados diferentes, optou-se por um aprofundamento da pesquisa, a fim de buscar conclusões mais palpáveis, momento em que se contrapôs a realidade da Missão Sal da Terra (MG), com a VIVA RIO SAÚDE - VIVA Comunidade (RJ), em julho/2013.

Nesta medida, tendo por referência os sítios destas organizações na rede mundial de computadores (internet), partiu-se em busca de um primeiro referencial: a verificação do Regulamento de Compras destas organizações sociais, a fim de se examinar seu modus operandi em termos de contratação de bens, obras e serviços.

Foi possível verificar, por meio das respectivas páginas na rede mundial de computadores, a disponibilização dos Regulamentos de compras (Regulamento Próprio) por parte do IABAS (INSTITUTO DE ATENÇÃO 
BÁSICA E AVANÇADA À SAÚDE, 2015) e da VIVA RIO SAÚDE VIVA Comunidade (VIVA COMUNIDADE, 2012), não tendo encontrado a mesma disponibilidade no sítio da Missão Sal da Terra (MISSÃO SAL DA TERRA, 2015a).

O Regulamento de Compras de Contratação de Obras ou Serviços do IABAS prevê, em seu artigo 12, que a seleção de seus fornecedores será realizada pelas seguintes modalidades de procedimento de escolha: "I - Adesão de Atas de Registros de Preço; II - Cotação; III - Concorrência Simplificada e IV - Pregão Eletrônico", não havendo naquele documento, qualquer menção específica às ME's e EPP's, existindo um tratamento generalizado de "empresas".

O Regulamento de Compras de Contratação de Obras ou Serviços da VIVA RIO SAÚDE - VIVA Comunidade, por sua vez, prevê, em seu artigo 11, que a seleção de seus fornecedores será realizada por duas modalidades: “a) cotação de preços; b) Carta Consulta”. Existe também a possibilidade de realização de "Pregão" no caso de aquisição de bens e serviços comuns. Como acontece no caso do IABAS (RJ), não existe naquele documento, qualquer menção específica ao tratamento diferenciado dispensado a ME's e EPP's, havendo um tratamento generalizado de "fornecedor" ou "fornecedores".

Ademais não ter sido possível o acesso ao Regulamento Próprio da Missão Sal da Terra, em seu sítio público é possível verificar alguns editais de seus procedimentos unificados de compra. No link SAÚDE (MISSÃO SAL DA TERRA, 2015b), é possível verificar a existência de algumas modalidades de compras (certamente legitimadas por seu Regulamento de Compras) que usam a mesma terminologia da Lei Geral de Licitações, quais sendo: Concorrência Pública, Tomada de Preços e Pregão Presencial.

De toda forma, julgamos oportuno um aprofundamento no processo de compras destas entidades, tendo por base, o que denominamos de "processos licitatórios simplificados", donde foi possível notar: a Missão Sal da Terra (MG) possui uma cláusula que parece ser uma constante em seus editais que reafirma que "Não haverá qualquer ordem de privilégios entre as participantes, prevalecendo a estrita isonomia entre as mesmas" e ainda, não traz no corpo de seus instrumentos convocatórios qualquer menção ao tratamento diferenciado dado às ME's e EPP's, típico dos processos licitatórios firmados com o poder público; o IABAS (RJ), da mesma forma, não faz menção a qualquer princípio nem faz referência aos privilégios presentes na Lei 
Complementar 123/2006; a VIVA RIO SAÚDE - VIVA Comunidade, por sua vez, se utilizando do site do Banco do Brasil (2013) para divulgar seus processos licitatórios, faz clara menção ao tratamento diferenciado dispensado não só a micro e pequenas empresas, mas também às cooperativas.

É certo que a Lei Complementar 123/2006, especialmente em seus artigos 42 a 49, veio para reforçar a intenção do Governo de utilizar o poder de compra das micro e pequenas empresas, fomentar o crescimento das economias locais, incentivar a competitividade, na medida em que permite a redução dos preços ofertados à Administração em seus processos licitatórios e isso se faz independente de menção nos respectivos instrumentos convocatórios, como norma de ordem pública, como comando constitucional dotado de plenitude. O espírito da lei prevalece ademais quaisquer especificidades normativas. Neste sentido, nos coadunamos com o entendimento do Tribunal de Contas (apesar da polêmica que cerca o assunto) que em seu Acórdão 702/2007 (BRASIL, 2007) afirma que a ausência de previsão editalícia não impede a aplicação dos benefícios previstos nos artigos 45 e 46 da LC 123/2006.

De toda forma, cumpre sempre voltarmos para a realidade ora objeto de estudo, lembrando que estamos vendo toda a questão do tratamento diferenciado de micro e pequenas empresas sob a ótica do Terceiro Setor e não do Poder Público. Os entes do Terceiro Setor não podem se pautar pelas mesmas regras dos entes com os quais realiza contratos para gerir serviços públicos de extirpe, sob pena de se transformarem em mais um braço deste ente público, em uma "Administração indireta acidental". Seria preciso empreender um estudo mais aprofundado no sentido de acompanhar os motivos pelos quais os entes pesquisados optaram por não reforçar em seus processos licitatórios os privilégios de ME's e EPP's na busca pelo melhor preço, a fim de verificar se os mesmos não se valeriam do tratamento diferenciado no momento da realização de seus processos licitatórios, como questão de ordem pública e mandato constitucional pleno.

É certo que a VIVA Comunidade opta por seguir os ditames impostos pela Lei Complementar 123/2006, especialmente em seus artigos 42 a 49, que veio para reforçar a intenção do Governo de utilizar o poder de compra das micro e pequenas empresas, mas o que isto realmente significaria no universo que ora nos debruçamos? Agindo de forma a prever o tratamento diferenciado em seus procedimentos licitatórios simplificados, a VIVA Comunidade não estaria se fazendo confundir com a Administração Pública, 
em uma relação que realmente é a única dotada de privilégios? O que podemos afirmar é que não há de se confundir os entes do Terceiro Setor parceiros dos entes públicos, com estes entes da Administração direta ou indireta, sob pena de se descaracterizar toda a sistemática que separa tais modelos.

Por outro lado, importa refletir se a Missão Sal da Terra (MG) não incorreria em alguma ilegalidade/inconstitucionalidade ante a ausência em seus processos licitatórios simplificados do tratamento diferenciado dispensado a micro e pequenas empresas. Entendemos, por sua vez, que não. Primeiro, porque entendemos que a Missão Sal da Terra, como organização social que é, ainda que prestadora de serviços públicos relevantes, não pode ser colocada em uma situação análoga a de Administração Pública. Além do mais, ainda que em interpretação equivocada se colocasse a Missão Sal da Terra como obrigada a seguir os ditames legais que privilegiam micro e pequenas empresas, ainda assim, não estaríamos diante de qualquer irregularidade visto que julgamos que o tratamento diferenciado dispensado àquelas empresas é uma norma de ordem pública, e como comando constitucional dotado de plenitude, prevalece ademais quaisquer especificidades editalícias.

De toda forma, vale ressaltar que não nos intriga a ausência de tratamento diferenciado dispensado a micro e pequenas empresas em processos licitatórios realizados pelos entes do Terceiro Setor, nos intriga os entes do Terceiro Setor não se utilizarem dos expedientes privilegiados na busca pelo melhor preço. Não vemos, a princípio, justificativa plausível para não se utilizarem de tratamento que poderia os fazer cumprir o princípio da economicidade, o qual devem respeito. Por conta disto, fica a dúvida: será que realmente o tratamento diferenciado presente nos rituais licitatórios realizados pelos entes do Terceiro Setor serviriam à realização do princípio da economicidade e na busca pela melhor preço ou seriam verdadeiro impeditivo para sua obtenção? Certamente que estudos mais aprofundados merecem ser realizados.

De toda forma, é fato consumado, que um simples passar de olhos pelo mundo de compras e serviços ${ }^{2}$ dos entes que balizaram estas investigações é

\footnotetext{
2 Análise pautada nos dados de extratos de contratos do IABAS/ RJ em http://iabas.net/compras/ editais-encerrados/, nos extratos de contratos da Missão Sal da Terra/MG em (MISSÃO SAL DA TERRA, 2015b) e no item "consultar atas" do site do Banco do Brasil, responsável pelos certames da VIVA Comunidade (BANCO DO BRASIL, 2013).
} 
suficiente para concluir que seu universo de contratação é considerável, perpassando pelos mais diversos objetos contratuais (limpeza, fornecimento de refeições, vigilância, dentre outros). Verifica-se, conforme extratos dos contratos presentes nos sítios públicos respectivos, que é relativamente pequena a participação de micro e pequenas empresas no universo dos processos licitatórios simplificados realizados pelo IABAS (RJ) e pela VIVA RIO SAÚDE - VIVA Comunidade, sendo insignificante o número daquelas efetivamente contratadas. Mesmo na VIVA RIO SAÚDE - VIVA Comunidade, que explicitamente dispõe acerca do tratamento diferenciado dispensado a micro e pequenas empresas, a participação é acanhada (BANCO DO BRASIL, 2013), ocorrendo, muitas vezes, a desclassificação daquelas ao longo do processo licitatório ${ }^{3}$. Na Missão Sal da Terra (MG), que como o IABAS (RJ) não discrimina em seus processos licitatórios o tratamento diferenciado, a participação de micro e pequenas empresas é significativa e chega a ser maior do que as de outras formas societárias, inclusive nas formas de contratação direta, que se dão via processos de inexigibilidade e dispensa de licitação.

Difícil saber os reais motivos destas discrepâncias, se são diferentes as exigências do mercado mineiro para o mercado carioca, se o despreparo de micro e pequenas empresas para este tipo de licitação é maior em um ou outro Estado e se realmente a ausência de reforço do tratamento diferenciado que alcança micro e pequenas empresas teria alguma coisa correlação com estes resultados observados. Novos estudos certamente deverão ser empreendidos a fim de se ter base outras realidades, alargando o número de entes pesquisados e experiências comparadas, a fim de se buscar uma explicação ou mesmo um padrão para a omissão e a presença do tratamento diferenciado conferido a micro e pequenas empresas em processos licitatórios realizados pelo Terceiro Setor e se isto é capaz de trazer algum tipo de prejuízo aos mesmos.

De toda forma, podemos concluir preliminarmente que, na prática, ficam claras como são intrincadas as relações entre Primeiro, Segundo e Terceiro Setor e, de fato, a diferenciação entre tais setores se dá mais a nível conceitual do que real. $\mathrm{O}$ econômico, o social e o estatal estão em uma relação mais próxima e interligada do que qualquer diferenciação que as possa afastar.

3 Análise pautada no item "consultar atas" do site do Banco do Brasil, responsável pelos certames da VIVA Comunidade (BANCO DO BRASIL, 2013). 


\section{CONSIDERAÇÕES FINAIS}

As Microempresas e Empresas de Pequeno Porte representam a força de um Brasil empreendedor. Os privilégios e prerrogativas presentes na legislação complementar, nada mais são que uma resposta aos mandamentos constitucionais que reconhecem a necessidade de construir caminhos para a efetivação do empreendedorismo no país.

A reflexão presente neste estudo pretendeu acompanhar a realidade das ME's e EPP's, especialmente no universo de seus privilégios e prerrogativas, tendo por referência as obrigações firmadas na dinâmica de contratações instituídas com o dito Terceiro Setor. Invariavelmente objeto de críticas, o Terceiro Setor tem o constante desafio de demonstrar ao que veio, que não se trata apenas de um modelo pela metade, que orbita entre o público e o privado, sem quaisquer restrições. De fato, esta hibridez do regime causa insegurança principalmente entre aqueles que contratam com os entes do Terceiro Setor e promovem situações de completo "limbo", palco para irregularidades e para a ocorrência de um "Direito mais ou menos" (LUDWIG, 2002, p. 67). Quando enfrentam processos licitatórios que aqui denominamos de simplificados (somente para se contrapor aos processos licitatórios realizados pelo Poder Público), que tem uma dinâmica toda própria, as ME's e EPP's sentem na pele a incerteza causada por este regime de hibridez.

A abordagem investigativa empreendida, comparando as realidades de três organizações sociais que tem contrato de gestão na área da saúde, respectivamente com o Município de Uberlândia, Estado de Minas Gerais (Missão Sal da Terra) e o Estado do Rio de Janeiro (IABAS e VIVA RIO SAÚDE - VIVA Comunidade) e as contratações firmadas com ME's e EPP's, algumas conclusões pontuais se fazem necessárias: 1) não existe nos Regulamentos Próprios de compras e prestação de serviço de tais entes, a menção a qualquer tratamento privilegiado dispensado às micro e pequenas empresas; 2) A Missão Sal da Terra (MG) e o IABAS (RJ), em seus editais de compras e aquisição de bens ou serviços não privilegiam ME's e EPP's, enquanto a VIVA RIO SAÚDE - VIVA Comunidade (RJ) é clara em seus processos ao firmar "Tratamento aplicado: com tratamento diferenciado para ME/EPP/COOP"; 3) No âmbito de compras e contratações geridas pela Missão Sal da Terra, a participação de micro e pequenas empresas é maior do que na VIVA RIO SAÚDE - VIVA Comunidade e o IABAS (RJ); 4) Reflexões mais amplas acerca deste tema se fazem compulsórias, tendo por referência outras organizações sociais, na medida em que a amostragem ainda 
é muito pequena para alguma conclusão que venha a se firmar pela utilidade da sistemática de tratamento favorecido dado a micro e pequenas empresas no que se refere a seu relacionamento com o Terceiro Setor.

\section{REFERÊNCIAS}

BANCO DO BRASIL. Licitações. Disponível em: <http:// www.licitacoes-e.com.br/ aop/consultar-detalhes-licitacao.aop>. Acesso em: 21 jul. 2013.

BONAVIDES, Paulo. Curso de direito constitucional. 13. ed. São Paulo: Malheiros, 2003.

BRASIL. Plano diretor da reforma do aparelho do estado. Brasília: Ministério da Administração Federal e Reforma do Estado, 1995.

. Tribunal de Contas da União. Ata $\mathbf{n}^{0}$ 12, de 17 de abril de 2007. Disponível em: $<$ http://portal2.tcu.gov.br/portal/pls/portal/docs/ 2046216.PDF>. Acesso em: 22 maio 2013.

BRESSER PEREIRA, Luiz Carlos; GRAU, Nuria Cunill (Org.). O Público Não-Estatal na Reforma do Estado. Rio de Janeiro: Editora FGV, 1999.

COELHO, Simone de Castro Tavares. Terceiro setor: um estudo comparado entre o Brasil e Estados Unidos. São Paulo: SENAC, 2003.

FERNANDES, Rubens C. Privado, porém público: o terceiro setor na América Latina. 2. ed. Rio de Janeiro: Rélume Dumará, 1994.

GONÇALVES, Pedro. Entidades privadas com poderes públicos. Coimbra: Almedina, 2005.

INSTITUTO DE ATENÇÃO BÁSICA E AVANÇADA À SAÚDE. Regulamento de compras e contratação de obras e serviços. Disponível em: <http://www.iabas.org.br/IABAS-V0/licitacao/ regulamento_de_compras_iabas.pdf>. Acesso em: 11 maio 2015. 
IOSCHPE, Evelyn Berg. $\mathbf{3}^{\mathbf{0}}$ setor: desenvolvimento sustentado. São Paulo: Paz e Terra, 2005.

JUSTEN FILHO, Marçal. O estatuto da microempresa e as licitações públicas. São Paulo: Dialética, 2007.

LUDWIG, Marcos de Campos. Direito público e direito privado: a superação da dicotomia. In: COSTA, Judith Martins (Org.). A reconstrução do direito privado. São Paulo: Revista dos Tribunais, 2002. v. 1.

MISSÃO SAL DA TERRA. Disponível em: $<$ http:// www.missaosaldaterra.org.br/index.php\#>. Acesso em: 11 maio 2015a.

. Saúde. Disponível em: $<$ http://www.missaosaldaterra.org.br/ index.php?pg=saude\&id=31\#>. Acesso em 11 maio 2015b.

MONTAÑO, Carlos. Terceiro setor e questão social: crítica ao padrão emergente de intervenção social. São Paulo: Cortez, 2005.

MOREIRA NETO, Diogo de Figueiredo. Mutações do direito administrativo. Rio de Janeiro: Renovar, 2000.

NOVAIS, Jorge Reis. Contributo para uma teoria do Estado e do direito: do estado de direito liberal ao estado social e democrático de direito. Coimbra: Coimbra, 1987.

OLIVEIRA, Gustavo Justino de. Direito do terceiro setor. Belo Horizonte: Fórum, 2008.

PIMENTA, Solange Maria; SARAIVA, Luiz Alex Silva; CORRÊA, Maria Laetitia. Terceiro setor: dilemas e polêmicas. São Paulo: Saraiva, 2008.

RIFKIN, Jeremy. Identidade e natureza do terceiro setor. In: IOSCHPE, Evelyn Berg (Org.). $3^{\circ}$ setor: desenvolvimento sustentado. São Paulo: Paz e Terra, 2005. 
SALAMON, Lester; ANHEIER, Helmut. The emerging sector: an overview. Baltimore: Manchester University Pres, 1994.

SANTOS, José Anacleto Abduch. Licitação e terceiro setor. In:

OLIVEIRA, Gustavo Justino de. Terceiro setor: empresas e estado novas fronteiras entre o público e o privado. Belo Horizonte: Fórum, 2007.

VIVA COMUNIDADE. Regulamento para aquisição de bens e contratação de obras, serviços e locações. Rio de Janeiro, 1 de junho de 2012. Disponível em: <http://www.vivacomunidade.org.br/wp-content/ arquivos/licitacao/regulamento_compras_servicos.pdf $>$. Acesso em: 11 maio 2015.

Submetido em: $12 / 04 / 2013$ Aprovado em: 25/10/2013

Como citar: MIRANDA, Napoleão; SILVA, Daniela Juliano. Micro e pequenas empresas contratadas do terceiro setor contratante de obras e serviços públicos. Scientia Iuris, Londrina, v.19, n.1, p.185-204, jun.2015. 